\title{
Assessment of Prevalence and Related Factors of Diarrheal Diseases among Under-Five Year's Children in Debrebirehan Referral Hospital, Debrebirehan Town, North Shoa Zone, Amhara Region, Ethiopia
}

\author{
Ayele Mamo, Awraris Hailu \\ Debre Birhan Health Science College, Debre Birhan, Ethiopia \\ Email: ayelemamo12@gmail.com
}

Received 26 February 2014; revised 1 April 2014; accepted 11 April 2014

Copyright (C) 2014 by authors and OALib.

This work is licensed under the Creative Commons Attribution International License (CC BY). http://creativecommons.org/licenses/by/4.0/

(c) (i) Open Access

\begin{abstract}
Background: Diarrheal diseases are one of the top (major) leading causes of under-five morbidity, mortality and under nutrition in developing countries. In African countries including Ethiopia, each child on average suffers from five episodes of diarrhea per year while the two-week prevalence ranges from $10 \%$ to $40 \%$ in different parts of Ethiopia. Objective: To assess prevalence and associated factors for the occurrence of diarrhea diseases among the under-five year's children in Debrebirehan referral hospital. Method: A facility-based cross sectional study design was conducted among 483 children less than 5 years of age who came to Debrebirehan referral hospital from February 1, 2013 to June 30, 2013. Data were collected, entered analyzed by using SPSS statistical software version 16.0. A logistic regression model was used to associated factors for the occurrence of diarrhea diseases. Results: The prevalence of diarrhea among mothers and underfive children was $9.3 \%$ and $31.7 \%$, respectively. Occupation of mothers (private workers) [(AOR: 2.004, 95\% CI: (1.167 - 3.442)], occupation of fathers (farmers) [AOR: 1.427, 95\% CI: (1.224 1.812)], maternal history of recent diarrhea [(AOR: 1.042, 95\% CI: (1.015 - 1.219)], houses having one room [AOR: 1.297, 95\% CI: (1.097 - 1.906) and houses having two rooms [AOR: 1.151, 95\% CI: (1.032 - 1.716)], living with cattle in one house [AOR: 1.297, 95\% CI: (1.097 - 1.906)], address (rural) [AOR: 2.527, 95\% CI: (1.847 - 7.538)], feeding of gruel for children [AOR: 3.046, 95\% CI: (1.408 6.587)], feeding of adult's food for children [(AOR: 3.703, 95\% CI: $(1.324-10.354)]$, method of dipping to take water from water containers [AOR: 1.371, 95\% CI: (1.137 - 1.607) \& water storage
\end{abstract}


container without cover [(AOR: 1.304, 95\% CI: (1.110 - 1.836)] had significant association with diarrheal diseases. Conclusion and Recommendation: In this study, the prevalence of diarrheal diseases was very high and major problem among under-five children. The health institutions efforts should be strengthened to decrease factors which increase diarrheal diseases.

\title{
Keywords
}

\author{
Diarrhea, Morbidity, Mortality, Under-Five Year
}

\section{Introduction}

\section{Background}

Diarrheal disease remains a leading cause of mortality and morbidity in children of the developing world. In developing countries, the average annual incidence rate of diarrhea in under-fives is estimated to be 2.6 episodes. It is also estimated that there are 100 million episodes and 3.3 million deaths occurring each year among children of under-five years of age [1]. In Africa, a child experiences five episodes of diarrhea per year, and 800,000 children die each year from diarrhea and dehydration [2]. Diarrhea is also responsible for $25 \%$ to $75 \%$ of all childhood diseases and account for about $14 \%$ of outpatient visits, $16 \%$ hospital admissions [3]. In addition to the excess mortality and morbidity, diarrhea predisposes children to malnutrition, which makes children highly susceptible to other infections [4].

In Ethiopia, morbidity reports and community-based studies have shown that diarrheal disease is a major public health problem that causes morbidity and mortality in children [5] [6]. Morbidity-Mortality-and Treatment (MMT) surveys conducted in Ethiopia in 2000 at different time's revealed five diarrheal episodes per child/year; and the two-week incidence rate to be $16 \%$. The diarrhea associated mortality rate is about 10/1000 under-five population [4] [7]. Studies conducted in central rural Ethiopia revealed that diarrhea is one of the common causes of under-five mortality, accounting for about $8.4 \%$ to $27 \%$ of all deaths [8] [9]. Recent estimates indicate that the two-week period prevalence of diarrhea in under-five children in Ethiopia is about 24 percent. [6]. Children's health is affected by environmental conditions as well as by their family's socio-economic status [10]. Studies done by WHO pointed out those poor environmental conditions were strongly associated with the risk of diarrheal disease [11]. Maternal practices related to hygiene, breastfeeding, sanitary food preparation and appropriate weaning practices are also potentially important determinants in the occurrence of diarrhea in children. On the other hand, the relationship between childhood diarrhea and parental socioeconomic, behavioral and household environmental factors wasn't consistent [12]-[14].

There is a general agreement that the cause of child mortality and morbidity in developing countries is multifactorial. The child's survival depends on the interaction of socioeconomic, biological, behavioral and environmental factors [15] [16]. Hence, it is very important to see the relation and interaction of these factors to understand child survival. However, information on these factors is either scarce or inadequate [5]. Very limited information on the effects of socioeconomic, behavioral and environmental factors are incorporated in the few studies conducted on childhood diarrhea.

According to the information 2005 report from the North Showa zonal health office, diarrhea is the first leading disease from the top ten diseases in this zone. Therefore, this study will be very important to fill this gap.

\section{Literature Review}

\subsection{Magnitude and Risk Factors of Diarrheal Morbidity}

According to a follow-up study in Butajira, the incidence of diarrhea was about two episodes/person-year [19]. A community based study conducted in Keffa-Sheka Zone, southern Ethiopia, found a two-week childhood diarrhea prevalence of 15 percent [20]. Another study from Jimma town, southwest Ethiopia, showed a prevalence of 36.5 percent [21].

A study done on patterns of childhood morbidity in Tigray Region had shown 3.05 diarrheal episodes per 
child per year [22]. Another study on determinant of household illness prevalence in Gondar showed that diarrhea was one of the three most frequently occurring symptoms, accounting for $11.4 \%$ of the overall illness prevalence [23]. A study done Jimma zone on diarrheal disease among under-five children found a two-week prevalence of 33.7 percent [24].

The factors that potentially determine the occurrence of diarrhea in children include malnutrition, poor personal hygiene, environmental problems, water availability and quality, unhygienic feeding practices, improper use of latrines, early discontinuation of breastfeeding, child's age, maternal education and household income [11] [17].

\subsection{Diarrheal Morbidity and Socioeconomic Factors}

Socioeconomic factors may affect, directly and indirectly, environmental, behavioral, nutritional, demographic risk factors with the exception of age and sex [27]. Therefore, differences in rates of diarrhea by socioeconomic status are mainly due to differences in childcare practices, such as preparation of weaning foods, boiling of drinking water, or personal hygiene practices [10] [12] [18].

Several studies on determinants of child health revealed that child survival in developing countries is highly associated with maternal education, more than with any other socioeconomic variables [25].

\subsection{Diarrheal Morbidity and Environmental Factors}

Children in urban areas where proper sanitation and water are available, and where modern treatment is more frequent will have a lower prevalence of diarrhea. Studies indicated that children living in urban areas were less likely to have diarrhea compared to those in rural areas [2] [19].

A study that assessed environmental determinants of childhood diarrhea, and another study from the Republic of Congo revealed that children coming from households that obtained water from protected sources were less likely to have diarrhea as compared to those who got their water supply from unprotected sources [12] [20]. A study that was done to determine the prevalence of childhood diarrhea in North Gondar Zone, northwest Ethiopia, indicated that use of unprotected water sources was significantly associated with diarrheal morbidity [28].

A study done in Jimma town indicated that in households without a latrine, and where feces are left deposited in the yard, or house, infant mortality was 2.76 times higher than in households where latrine was used [29]. A study from Zimbabwe revealed that the absence of refuse disposal pit latrine was associated with higher diarrhea morbidity [26].

A study done in Kefa Sheka zone observed an inverse relationship between number of rooms and diarrhea morbidity [20]. Another study from Jimma town also revealed that children living in houses with three or more rooms had less diarrhea [21].

\subsection{Diarrheal Morbidity and Behavioral Factors}

Behavioral factors play a primary role in the epidemiology of diarrheal diseases. Risk of exposure to diarrhea causing organisms may be affected by behavior patterns common to the population, such as, defecation habits and personal hygiene and by patterns of food preparation, storage and consumption [30].

Studies suggested that maternal practices related to hygiene, breastfeeding, food preparation, appropriate weaning practices, and healthcare are important determinants of diarrheal disease incidence [12]. It has been reported that partially breast fed or non-breastfed infants have about two to five times higher episodes of diarrhea experienced by exclusively breastfed infants [11] [16].

In study of the rural part of Ethiopia on breastfeeding and the occurrence of acute childhood diarrhea found out that the risk of developing diarrheal disease in partially breastfed infants was five-times higher than that of infants exclusively on breast milk [4]. The study showed that exclusive breastfeeding was an important predictor of the occurrence of diarrheal disease in infants less than six months of age. Study done in Gambia demonstrated heavy contamination of gruels used as complementary foods [3].

Availability of improved water sources or latrine alone will not reduce diarrhea morbidity, without a change in behavior that affects hygiene practice [12] [14]. A study revealed that the prevalence of diarrhea was significantly higher in children from households where water is obtained from storage container by dipping than in those where water is obtained by pouring [20] [31]. 


\section{Objectives}

\subsection{General Objective}

To assess the prevalence and associated factors for the occurrence of diarrhea diseases among under-five year's children.

\subsection{Specific Objectives}

- To determine the prevalence of diarrhea diseases.

- To assess factors that were associated with diarrheal diseases.

\section{Methods and Materials}

\subsection{Study Area}

Debrebirehan is the capital town of the North Shoa zone which is located at about $130 \mathrm{Km}$ of North East of Addis Ababa. Debrebirehan hospital is found in Amhara national regional state, North Shoa zone.

\subsection{Study Design and Period}

Cross section study design was conducted to assess the prevalence rate and associated factors for the occurrence of diarrhea diseases among the under-five year's children. The study was conducted from February 1, 2013 to June 30, 2013.

\subsection{Study Variables}

\subsubsection{Outcome (Dependent) Variable}

Episode of diarrhea in a child.

\subsubsection{Explanatory (Independent) Variable}

1) Socioeconomic status includes family economic status, place of residence, household size, maternal age, education, ethnicity, number of children, occupation, marital status, religion, etc.

2) Environmental sanitation includes type of water source, distance to the water source, amount of daily water consumption availability of latrine, number of rooms, livestock in house, refuse disposal, etc.

3) Behavioral factors includes method of water drawing and storage, feeding practices, action for diarrhea, duration of breast-feeding, time of introducing supplementary feeding, etc.

\subsection{Operational Definitions}

1) Diarrhea is defined as having three or more loose or watery stools in a twenty-four hours period, as reported by the mother/caretaker of the child.

2) Number of rooms is defined as any partition of a house that is intended to separate the rooms for different purposes.

3) Refuse: includes such solid wastes as ash, cow dung, home-sweepings; but not human excreta.

4) A child who was receiving no food, solid or liquid, other than breast milk at the time of the survey was considered as exclusively breast-fed.

5) Mixed feeding: a child who was receiving food, solid or liquid, in addition to breast milk at the time of the survey.

6) No breast-feeding: a child who was not receiving breast milk at the time of the survey.

The child may eat food/liquid that was prepared for adults or prepared separately for him/her.

7) Index child: refers to a child that was included in the study from a household to have information on the demographic and health characteristics, and also to calculate the prevalence and incidence of diarrhea.

8) Prevalence: the number of diarrhea cases at the time of the interview divided by the total number of households included in the study. 


\subsection{Source and Study Population}

The study population for the study was all under five children who came to the Debrebirehan referral hospital. The source population was all under-5 year's children living in the zone.

\subsection{Sample Size Determination}

The prevalence of diarrhea for the areas covered by the Debrebirehan town was not known from previous studies. Other studies done in different parts of the Country but these were not latest. Hence, the national prevalence of diarrhea for under-five children was taken from the report of the Demographic and Health Survey 2011

(13\%) to calculate the sample size. By using this assumption: $\mathrm{p}=13 \%=0.13, \mathrm{Z} \frac{\alpha}{2}=$ critical value at $95 \%$ confidence interval (1.96)

$$
\begin{aligned}
& \mathrm{d}=\text { desired precision }(3 \%) \\
& \mathrm{Z}^{2} \frac{\alpha}{2} \mathrm{P}(1-\mathrm{p}) \\
& \mathrm{n}=\text {------- } \\
& \mathrm{d}^{2} \\
& \mathrm{n}=\frac{1.96 \times 1.96 \times 0.13 \times 0.87}{0.03 \times 0.03}=482.761
\end{aligned}
$$

The calculated total sample size for this study will be 483 .

\subsection{Sampling Procedure}

The sampling technique used in this study was a taking participant using every other client fashion. The data (questionnaire) were recorded or collected for under five children patients who come to the referral hospital using every other client fashion. The patients' mother or caretakers (the under five children's mother or caretakers) was interviewed in face-to-face by data collectors with Amharic language.

\subsection{Data Collection Instruments and Data Collection Procedure}

A structured questionnaire was used to collect data. The questionnaire was adapted from the Ethiopian BSS questionnaire. Four qualified nurses was trained for two days and participated in the pre-test and data collection. The pre-test was conducted on 25 under five children in Debrebirehan referral hospital which were out of the sampled population. The principal investigator was closely followed and supervised data collection day to day. Incomplete and inconsistent data were identified and necessary corrections were made during the data collection time.

\subsection{Data Processing and Analysis}

Data entry, cleaning, editing and analysis were done using SPSS statistical software version 16.0. The frequency distribution of all variables was examined to check for data entry errors (e.g. unrecognized or missing codes, out of range values). For each variable, frequencies, odds ratios (OR), 95\% CI and p-value at 5\% will be computed to assess the process and degree of association between dependent and independent variables. To identify independent variables which had statistically significant association with the presence or absence of diarrhea diseases bivariate \& univariate analysis were computed. The data were described and presented using narrative text and tables.

\subsection{Data Quality Assurance}

The questionnaire was structured and standardized. The data collectors were trained for two days. The instruments were pre-tested on 5\% of the sample population/who was not the part of the study group. Based on the result of pre-testing a necessary revision was undertaken. Data collectors submitted the collected data to the supervisors on daily basis. The name of interviewer was recorded so as to enhance the responsibility to any in- 
complete question. Data coding and data entry was checked at the beginning and at the midway stage of the work. Data cleaning was conducted at the end of data entry.

\subsection{Ethical Consideration}

Permission was obtained from the ethical clearance committee of Debrebirehan Health Science College and medical officer of the referral hospital. Informed verbal consent was obtained from the mothers/caretakers of the children. Mothers/caretakers were give their consent for participation in the study and all information that was obtain about the subjects as well as the mothers/caretakers was keep confidential.

\section{Results}

\subsection{Socio-Economic Characteristic}

From this study, the prevalence of diarrhea for under-five children in Debrebirehan referral hospital was found $31.7 \%$. A total of 483 clients were included in this study. Out of these respondents, 479 (99.2\%) were mothers and $4(0.8 \%)$ were caretakers. More than $80 \%$ of the mothers were below the age of 36 years (Table 1$)$. The majority of mothers were married 476 (98.6\%), Christian by religion 469 (97.1). About $81 \%$ of the fathers were

Table 1. Socioeconomic characteristics of the respondents, Debrebirehan town, Debrebirehan zonal hospital June 2013 (n = 483).

\begin{tabular}{|c|c|c|c|}
\hline Variables & Response category & Frequency & Percent \\
\hline \multirow{2}{*}{ Relation of the respondent to the child } & Mother & 479 & 99.2 \\
\hline & Caretaker & 4 & 0.8 \\
\hline \multirow{3}{*}{ Age of the mother } & $18-26$ & 167 & 34.6 \\
\hline & $27-35$ & 227 & 47.0 \\
\hline & $36-40$ & 89 & 18.4 \\
\hline \multirow{3}{*}{ Marital status of mother } & Married & 476 & 98.6 \\
\hline & divorce & 2 & 0.4 \\
\hline & single & 5 & 1.0 \\
\hline \multirow{2}{*}{ Religion of parents } & Christian & 469 & 97.1 \\
\hline & Muslim & 14 & 2.9 \\
\hline \multirow{4}{*}{ Ethnic group of parents } & Amhara & 408 & 84.5 \\
\hline & Oromo & 61 & 12.6 \\
\hline & Tigray & 12 & 2.5 \\
\hline & Others & 2 & 0.4 \\
\hline \multirow{3}{*}{ Educational level of mother } & Formal education & 385 & 79.7 \\
\hline & Read only & 27 & 5.6 \\
\hline & Totally no education & 71 & 14.7 \\
\hline \multirow{3}{*}{ Occupation of the mother } & House wife & 259 & 53.6 \\
\hline & Government employee & 110 & 22.8 \\
\hline & Private gainful work & 114 & 23.6 \\
\hline \multirow{3}{*}{ Educational level of the father } & Formal education & 391 & 81.0 \\
\hline & Read only & 36 & 7.5 \\
\hline & Totally no education & 56 & 11.5 \\
\hline \multirow{3}{*}{ Occupation of the father } & Government employee & 179 & 37.1 \\
\hline & Merchant & 189 & 39.1 \\
\hline & Farmer & 115 & 23.8 \\
\hline
\end{tabular}


literate. One hundred eighty nine (39.1\%) fathers were merchants, 179 (37.1) were governments and 115 (23.8\%) were farmers.

\subsection{Environmental Characteristics}

Floor of most houses (58.4\%) were made from wood and others from mud and cement. From the total 483 respondents $63.5 \%$ of the total houses had three and more than three rooms. Only $17 \%$ of the total houses had one room. The majority of the respondents (96.3\%) were not kept cattle in their houses where as 18 (3.7\%) of respondents were lived with cattle in their houses. About $87.8 \%$ of the houses had either privately owned or shared latrine where as $12.2 \%$ of the houses had not latrine. About 260 (53.8\%) of the respondents disposed their refuse by burning, 104 (21.5\%) of the respondents disposed by burying the refuse in a pit and 72 (14.9\%) of the respondents disposed in a garbage can. Only about $9.7 \%$ of the respondents disposed the refuse in open field (Table 2).

Three hundred eighty four (79.5\%) respondents were used pipe/protected well as the main source of water

Table 2. Environmental characteristics of the respondents in Debrebirehan zonal hospital, June 2013 ( $n=483)$.

\begin{tabular}{|c|c|c|c|}
\hline Variables & Response category & Frequency & Percent \\
\hline \multirow{3}{*}{ Types of floor material of the living house } & Mud & 191 & 39.5 \\
\hline & Cement & 10 & 2.1 \\
\hline & Wood & 282 & 58.4 \\
\hline \multirow{2}{*}{ Types of roof material of the living house } & Thatched & 90 & 18.6 \\
\hline & Corrugated iron sheet & 393 & 81.4 \\
\hline \multirow{2}{*}{ Do animals live with family in one house } & Yes & 18 & 3.7 \\
\hline & No & 465 & 96.3 \\
\hline \multirow{5}{*}{ Number of rooms } & 1 & 82 & 17.0 \\
\hline & 2 & 94 & 19.5 \\
\hline & 3 & 104 & 21.5 \\
\hline & 4 & 183 & 37.9 \\
\hline & 5 & 20 & 4.1 \\
\hline \multirow{2}{*}{ Is latrine available } & Yes & 424 & 87.8 \\
\hline & No & 59 & 12.2 \\
\hline \multirow{4}{*}{ How do you dispose refuse? } & Pit & 104 & 21.5 \\
\hline & Burning & 260 & 53.8 \\
\hline & Open field & 47 & 9.7 \\
\hline & Garbage can & 72 & 14.9 \\
\hline \multirow{2}{*}{ Source of water for drink } & Pipe/protected well & 384 & 79.5 \\
\hline & Unprotected well/spring & 99 & 205 \\
\hline \multirow{3}{*}{ Types of collection container } & Pot & 79 & 16.4 \\
\hline & Plastic & 55 & 11.4 \\
\hline & Jerry can bucket & 349 & 72.2 \\
\hline \multirow{2}{*}{ Way of transporting water to home } & In a covered container & 460 & 95.2 \\
\hline & In uncovered container & 23 & 4.8 \\
\hline \multirow{4}{*}{ Capacity of the container } & $10-20$ liters & 264 & 54.7 \\
\hline & 21 - 30 liters & 143 & 29.6 \\
\hline & 31 - 40 liters & 3 & 0.6 \\
\hline & 41 - 60 liters & 73 & 15.1 \\
\hline
\end{tabular}


whereas and 99 (20.5\%) used unprotected well/spring as the main source of water. About 349 (72.2\%) respondents used Jerry can bucket to collect water and 79 (16.4\%) respondents used pot to collect water. About Four hundred sixty (95.2\%) respondents used a covered container, 23 (4.8\%) respondents used uncovered container to fetch water (Table 2).

\subsection{Behavioral and Child Demographic and Health Characteristic}

Of the total 483 mothers/caretakers, 74 (15.3\%) mothers breastfed their children exclusively. Four hundred nine (84.7\%) mothers/caretakers fed their child other types of food in addition to the breast milk. About half (50.9\%) mothers/caretakers fed their child cow's milk in addition to the breast milk, followed by powder milk, 132 (27.3\%). Out of the total 483 mothers/caretakers who started supplementary feeding for their children 92 (19\%) started before the child reached 6 months, and 327 (67.7\%) after the age of 6 months. About 180 (37.3\%) mothers fed their children using their hands, 169 (35\%) mothers fed their children using bottle and 134 (27.7\%) mothers fed their children using cup and spoon (Table 3).

\subsection{Demographic and Health Characteristics of the Index Children}

Only 45 (9.3\%) children's mothers had diarrhea during the interview. Out of the 153 mothers/caretakers whose children got diarrhea at the time of the survey, about 132 (86.3\%) mothers claimed that they took their child to the nearby health post or other health institution to seek medical help. Of the total children, nearly half of children (48.7\%) age were from 7 - 14 months and 36\% children age was above 24 months.

Out of 483 children, 258 (53.4\%) children were males. One hundred and eighty-five (38.3\%), 178 (36.9\%), 72 (14.9\%) 48 (9.9\%) children were born first, second, third and fourth (beyond) respectively (Table 4). Of the total 483 children whose age was 9 months and above at the time of the survey, 344 (71.2) children were immunized for measles. Majority of children (96.1\%) had diarrhea lasting less than 14 days. Out of 153 children who had diarrhea during the interview, 128 (83\%) children had watery diarrhea, and only 26(17\%) children had bloody and mucosal diarrhea. Out of the total 483 mothers/care takers, 368 (76.2\%) mothers/caretakers were lived in urban (Table 4).

\subsection{Association b/n Socio-Economic Factors and Diarrheal Diseases}

In the Bivariate analysis and Multivariate (both) logistic regressions analysis, mothers’ and fathers' occupation

Table 3. Behavioral aspects (maternal child health care and health practice) in Debrebirehan zonal hospital, June 2013 ( $\mathrm{n}=$ 483).

\begin{tabular}{|c|c|c|c|}
\hline Variables & Response category & Frequency & Percent \\
\hline \multirow{2}{*}{ Child take other food } & Yes & 409 & 84.7 \\
\hline & Only breast milk & 74 & 15.3 \\
\hline \multirow{2}{*}{ Prepare child food separately } & Yes & 396 & 82.0 \\
\hline & No & 87 & 18.0 \\
\hline \multirow{4}{*}{ Type of food child receive } & Cow's milk & 246 & 50.9 \\
\hline & Powder milk & 132 & 27.3 \\
\hline & Gruel & 68 & 14.1 \\
\hline & Adult's food & 37 & 7.7 \\
\hline \multirow{3}{*}{ Used material for child feeding } & Hand & 180 & 37.3 \\
\hline & Cup and spoon & 134 & 27.7 \\
\hline & Bottle & 169 & 35.0 \\
\hline \multirow{2}{*}{ Water storage container has cover } & Yes & 431 & 89.2 \\
\hline & No & 52 & 10.8 \\
\hline \multirow{2}{*}{ Take water from drinking storage container by } & Pouring & 395 & 81.8 \\
\hline & Dipping & 88 & 18.2 \\
\hline
\end{tabular}


Table 4. Demographic and health characteristics of the index children, in Debrebirehan zonal hospital, June 2013 (n = 483 ).

\begin{tabular}{|c|c|c|c|}
\hline Variables & Response category & Frequency & Percent \\
\hline \multirow{3}{*}{ Age of index child } & $0-6$ & 74 & 15.3 \\
\hline & $7-24$ & 235 & 48.7 \\
\hline & $>24$ & 174 & 36 \\
\hline \multirow{2}{*}{ Sex of the index child } & Male & 258 & 53.4 \\
\hline & Female & 225 & 46.6 \\
\hline \multirow{4}{*}{ Birth order of the child } & First & 185 & 38.3 \\
\hline & Second & 178 & 36.9 \\
\hline & Third & 72 & 14.9 \\
\hline & Fourth and above & 48 & 9.9 \\
\hline \multirow{2}{*}{ Mother has hx of diarrhea } & Yes & 45 & 9.3 \\
\hline & No & 438 & 90.7 \\
\hline \multirow{2}{*}{ Did you breastfed your child } & Yes & 477 & 98.8 \\
\hline & No & 6 & 1.2 \\
\hline \multirow{3}{*}{ Current breastfeeding status } & Exclusive breastfeeding & 72 & 14.9 \\
\hline & Partial breastfeeding & 282 & 58.4 \\
\hline & Not breastfeeding & 129 & 26.7 \\
\hline \multirow{3}{*}{ Time for starting supplementary food } & $<6$ & 92 & 19.0 \\
\hline & $>6$ & 327 & 67.7 \\
\hline & Not start & 64 & 13.3 \\
\hline \multirow{2}{*}{ Child receive measles vaccination } & Yes & 344 & 71.2 \\
\hline & No & 139 & 28.8 \\
\hline \multirow{2}{*}{ Do your child have diarrhea today } & Yes & 153 & 31.7 \\
\hline & No & 330 & 68.3 \\
\hline \multirow{2}{*}{ For how long the diarrhea last } & Less than 14 days & 148 & 96.1 \\
\hline & Greater than 14 days & 6 & 3.9 \\
\hline \multirow{2}{*}{ The types of diarrhea that child had } & Watery & 128 & 83 \\
\hline & Blood and mucus & 26 & 17 \\
\hline \multirow{3}{*}{ Action taken for diarrhea treatment } & Take child to health institution & 132 & 27.3 \\
\hline & Take child to traditional healers & 14 & 2.9 \\
\hline & Increased feeding & 7 & 1.4 \\
\hline \multirow{2}{*}{ Address } & Urban & 368 & 76.2 \\
\hline & Rural & 115 & 23.8 \\
\hline
\end{tabular}

were significantly associated with diarrheal morbidity. Children whose mothers were private workers were about two times more likely to had diarrhea compared to children whose mothers were housewives [AOR: 2.004, 95\% CI: $(1.167$ - 3.442)]. Children whose fathers were farmers were more likely to have diarrhea compared to children whose were government employee [AOR: 1.427, 95\% CI: (1.224 - 1.812)] (Table 5).

\subsubsection{Association b/n Environmental Factors and Diarrheal Diseases}

In both logistic regressions analysis, children who lived in houses which had one [AOR: 1.297, 95\% CI: (1.097 1.906) and two rooms [AOR: 1.151, 95\% CI: (1.032 - 1.716)] had significant association with childhood diarrheal diseases. Living with cattle in one house had significant association with childhood diarrheal diseases [AOR: 1.297, 95\% CI: $(1.097$ - 1.906)]. Children who live in the rural areas were about two times more likely to 
Table 5. Selected socio-economic factors in relation to childhood diarrheal diseases, June 2013 ( $\mathrm{n}=483$ ).

\begin{tabular}{|c|c|c|c|c|}
\hline \multirow{2}{*}{ Variables } & \multicolumn{3}{|c|}{ Diarrhea } & \multirow{2}{*}{ Adjusted OR (95\% CI) } \\
\hline & Yes (\%) & No (\%) & OR (95\% CI) & \\
\hline \multicolumn{5}{|l|}{ Educational level of mother } \\
\hline -Formal education & 107 (27.8\%) & $278(72.2 \%)$ & 1 & 1 \\
\hline -Read and write & $14(53.8 \%)$ & $12(46.2 \%)$ & $1.33(1.148-1.736)^{*}$ & $0.576(0.214-1.546)$ \\
\hline -Totally no education & 32 (44.4\%) & $40(55.6 \%)$ & $1.481(1.287-1.806)^{*}$ & $0.751(0.357-1.582)$ \\
\hline \multicolumn{5}{|l|}{ Occupation of mother } \\
\hline -House wife & $100(38.6 \%)$ & 159 (61.4\%) & 1 & 1 \\
\hline -Government employee & $29(26.4 \%)$ & $81(73.6 \%)$ & $1.757(0.074-2.874)$ & $1.072(0.552-2.084)$ \\
\hline -Private gainful work & $24(21.1 \%)$ & $90(78.9 \%)$ & $2.358(1.409-3.948)^{*}$ & $2.004(1.167-3.442)^{*}$ \\
\hline \multicolumn{5}{|l|}{ Education level of father } \\
\hline -Formal education & $110(28.1 \%)$ & $281(71.9 \%)$ & 1 & 1 \\
\hline -Read and write & $17(47.2 \%)$ & $19(52.8 \%)$ & $1.438(1.219-1.873)^{*}$ & $1.219(0.349-4.253)$ \\
\hline -Totally no education & $26(46.4 \%)$ & $30(53.6 \%)$ & $1.452(1.256-1.798)^{*}$ & $1.548(0.421-5.695)$ \\
\hline \multicolumn{5}{|l|}{ Occupation of father } \\
\hline -Government employee & $44(24.6 \%)$ & 135 (75.4\%) & 1 & 1 \\
\hline -Merchant & $57(30.2 \%)$ & $132(69.8 \%)$ & $0.755(0.476$ - 1.196) & $0.667(0.368-1.211)$ \\
\hline -Farmer & $52(45.2 \%)$ & $63(54.8 \%)$ & $1.395(1.239-1.651)^{*}$ & $1.427(1.224-1.812)^{*}$ \\
\hline
\end{tabular}

Note: $\mathrm{p}<0.05,{ }^{*}=$ Significant.

have diarrheal diseases than the children who live in the urban areas [AOR: 2.527, 95\% CI: (1.847 - 7.538)] (Table 6).

\subsubsection{Association $\mathrm{b} / \mathrm{n}$ Behavioral Factors and Diarrheal Diseases}

Children who fed gruel and adult's food were about three and four times more likely to have diarrhea than those who fed cow's milk [AOR: 3.046, 95\% CI: (1.408 - 6.587) and (AOR: 3.703, 95\% CI: (1.324 - 10.354) respectively].

Method of drawing/pouring water from storage container, and covering water storage container had significant association with diarrheal diseases [AOR: 1.371, 95\% CI: (1.137 - 1.607) and (AOR: 1.304, 95\% CI: (1.110 1.836), respectively]. In this study, maternal diarrheal diseases was significantly associated with childhood diarrheal diseases [AOR: 1.042, 95\% CI: (1.015 - 1.219)] (Table 7).

\section{Discussion}

The findings of this study revealed that the prevalence of diarrhea in under-fives was 31.7 percent. This figure was quite high compared with 15\% in Keffa-Sheka Zone [20], 13\% in the report of the Demographic and Health Survey 2011 [30], 18.6\% in the Republic of Congo and 11.4\% in Gondar [23] but lower than findings in Jimma town (36.5\%) [21] and in Jimmazone (33.7\%) [24].

According to this study, occupation of mother and father was associated significantly with diarrheal diseases. This is also supported with other studies done on occupation of parent [2] [13] [21].

In this study, children who lived in houses with one and two rooms had significant association with diarrheal diseases. Similarly, a study done in Kefa-Sheka zone observed an inverse relationship b/n number of rooms and diarrheal morbidity [20]. Another study from Jimma town also revealed that children living in houses with three or more rooms had less diarrheal diseases [21]. Living with cattle in the same house had shown significant association with childhood diarrheal diseases. Similarly, study done by WHO revealed that the presence of animals in a house also can be used as a measure of exposure to diarrhea-causing organisms [11].

In the present study, children who live in the rural areas were about two times more likely to have diarrheal 
Table 6. Selected environmental in relation to childhood diarrheal diseases, June 2013 (n= 483).

\begin{tabular}{|c|c|c|c|c|}
\hline \multirow{2}{*}{ Variables } & \multicolumn{3}{|c|}{ Diarrhea } & \multirow{2}{*}{ Adjusted OR (95\% CI } \\
\hline & Yes & No & Crude OR (95\% CI) & \\
\hline \multicolumn{5}{|c|}{ Animals living with family in same house } \\
\hline -Yes & $13(72.2 \%)$ & $5(27.8 \%)$ & $1.166(1.058-1.474)^{*}$ & $1.297(1.097-1.906)^{*}$ \\
\hline$-\mathrm{No}$ & $140(30.1 \%)$ & $325(69.9 \%)$ & 1 & 1 \\
\hline \multicolumn{5}{|l|}{ No of room in house } \\
\hline-1 & $34(41.5 \%)$ & 48 (58.5\%) & $1.157(1.034-1.721)^{*}$ & $1.239(1.047-1.211)^{*}$ \\
\hline-2 & $42(44.7 \%)$ & $52(55.3 \%)$ & $1.138(1.030-1.627)^{*}$ & $1.151(1.032-1.716)^{*}$ \\
\hline-3 & $30(28.8 \%)$ & $74(71.2 \%)$ & $0.274(0.060-1.255)$ & $0.253(0.054-1.195)$ \\
\hline-4 & $45(24.6 \%)$ & $138(75.4 \%)$ & $0.341(0.076-1.526)$ & $0.354(0.077-1.626)$ \\
\hline-5 & $2(10.0 \%)$ & $18(90.0 \%)$ & 1 & 1 \\
\hline \multicolumn{5}{|l|}{ Latrine available } \\
\hline -Yes & $121(28.5 \%)$ & $303(71.5 \%)$ & 1 & 1 \\
\hline -No & $32(54.2 \%)$ & 27 (45.8\%) & $0.337(0.194-0.586)^{*}$ & $1.923(0.286-12.932)$ \\
\hline \multicolumn{5}{|l|}{ Source of water for drink } \\
\hline -Pipe & $105(27.3 \%)$ & $279(72.7 \%)$ & 1 & 1 \\
\hline -Protected well/spring & $5(45.5 \%)$ & $6(54.5 \%)$ & $0.452(0.135-1.511)$ & $1.144(0.252-5.181)$ \\
\hline -Unprotected well/spring & $43(48.9 \%)$ & 45 (51.1\%) & $1.394(1.245-1.633)^{*}$ & $0.693(0.280-1.717)$ \\
\hline \multicolumn{5}{|l|}{ Address } \\
\hline Urban & $101(27.4 \%)$ & 267 (72.6\%) & 1 & 1 \\
\hline Rural & $52(45.2 \%)$ & $63(54.8 \%)$ & $1.458(1.297-1.706)^{*}$ & $2.527(1.847-7.538)^{*}$ \\
\hline
\end{tabular}

Note: $\mathrm{p}<0.05,^{*}=$ Significant.

Table 7. Selected demographic and behavioral aspects in relation to childhood diarrheal diseases, June 2013 ( $\mathrm{n}=483$ ).

\begin{tabular}{|c|c|c|c|c|}
\hline \multirow{2}{*}{ Variables } & \multicolumn{3}{|c|}{ Diarrhea } & \multirow{2}{*}{ Adjusted OR (95\% CI) } \\
\hline & Yes & No & Crude OR (95\% CI) & \\
\hline \multicolumn{5}{|l|}{ Type of food child receive } \\
\hline Cow’s milk & $93(37.8 \%)$ & $153(62.2 \%)$ & 1 & 1 \\
\hline Powder milk & 40 (30.3\%) & $92(69.7 \%)$ & $1.398(0.890-2.197)$ & $1.230(0.746-2.026)$ \\
\hline Gruel & $12(17.6 \%)$ & $56(82.4 \%)$ & $2.837(1.445-5.569)^{*}$ & $3.046(1.408-6.587)^{*}$ \\
\hline Adult's food & $8(21.6 \%)$ & $29(78.4 \%)$ & $2.203(1.967-5.023)^{*}$ & $3.703(1.324-10.354)$ \\
\hline \multicolumn{5}{|c|}{ Water storage container has cover } \\
\hline Yes & $123(28.5 \%)$ & 308 (71.5\%) & 1 & 1 \\
\hline No & $30(57.7 \%)$ & $22(42.3 \%)$ & $1.293(1.163-1.528)^{*}$ & $1.304(1.110-1.836)^{*}$ \\
\hline \multicolumn{5}{|c|}{ Take water from drinking storage container } \\
\hline Pouring & $107(27.1 \%)$ & $288(72.9 \%)$ & 1 & 1 \\
\hline Dipping & $46(52.3 \%)$ & $42(47.7 \%)$ & $1.339(1.211-1.545)^{*}$ & $1.371(1.137-1.607)^{*}$ \\
\hline \multicolumn{5}{|l|}{ Mother has hx of diarrhea } \\
\hline Yes & 40 (88.9\%) & $5(11.1 \%)$ & $1.043(1.017-1.113)^{*}$ & $1.042(1.015-1.219)^{*}$ \\
\hline No & $113(25.8 \%)$ & $325(74.2 \%)$ & 1 & 1 \\
\hline
\end{tabular}

Note: $\mathrm{p}<0.05,{ }^{*}=$ Significant. 
diseases than the children who live in the urban areas. Similarly, researches done in Eritrea and rural Ethiopia indicated that children living in urban areas were less likely to have diarrhea compared to those in rural areas [2] [19]. Children in urban areas where proper sanitation and water are available, and where modern treatment is more frequent will have a lower prevalence of diarrhea. This may be attributed to the difference between urban and rural areas in literacy status, type of water source and latrine availability.

On the other hand, type of food received by child had shown significant association with the occurrence of diarrheal diseases. The children who fed gruel had three times more likely diarrheal diseases than children who were cow's milk fed in both analyses. The children who fed adult's food had four times more likely diarrheal diseases than children who were cow's milk fed in both analyses. It has been reported that partially breastfed or non-breastfed infants have about two to five times higher episodes of diarrhea experienced than exclusively breastfed infants [11] [16].

Studies revealed that obtaining water from storage containers by dipping was a risk factor for diarrhea [14] [20]. Similar to these findings, the present study showed that children who live in households where water was dipped out were more likely to have diarrhea compared to those who live in households where water was poured out. Those children who lived in households where uncovered water storage container was more like to have diarrhea than their counterparts. Similarly, other study showed that water stored in an uncovered container was associated with the occurrence of diarrheal diseases [14].

In the aspect, maternal diarrhea disease status was found to be significant predictors of diarrheal disease in children. Similar finding was observed in Congo where maternal diarrheal morbidity was associated with a twofold increase in the odds for diarrheal disease in children [12]. This is so because mothers are food handlers of the family, and also they are usual childcare providers. Moreover, the care of the child may be compromised if the mother herself is sick.

\section{Limitations and Strengths of the Study}

\subsection{Limitations}

As being cross-sectional in the design, this study shared the drawbacks of similar cross sectional studies. In cross-sectional studies, it was difficult to entertain the seasonal differences in the occurrence of diarrheal diseases. The information on the prevalence of diarrhea might not reflect the actual situation that may be observed in the various seasons of the year, as the information on diarrhea was collected in a dry season. The other limitation was related to the definition of the term "diarrhea". There may be difference among mothers in perceiving their child's health. There was not enough financial support for studying this research during this time.

\subsection{Strengths}

The present study assessed the households' socioeconomic, environmental and behavioral characteristics that are considered to have effects on child health particular in diarrheal diseases. Considering multiple contributing factors that affect child health may help use the limited resources more effectively, by identifying the most important risk factors. The multiple factors considered in this study were analyzed using a stepwise logistic regression technique. This technique helps control for mediating and confounding factors, and also to identify the most important risk factors for proper intervention.

\section{Conclusion}

The overall results is this study suggest that living in rural areas, living with livestock in one house, occupation of parents, type of food child receive, child food handling practices, water handling practices and diarrheal history of mother were risk factors for the occurrence of diarrhea in under-five children.

\section{Recommendations}

Depend on this study finding, the authors recommend that IEC \& BCC should plan to encourage the awareness of mothers on associated factors of diarrheal diseases, improve the environmental condition, giving direction for health extension worker to teach the community about diarrheal diseases. Further study should be done to identify the possible factors that were responsible for the high prevalence of diarrhea for proper interventions. 


\section{Acknowledgements}

We would like to explain our deepest gratitude to the Debrebirehan health science college for financing this research. Our thanks also go to the staff of Debrebirehan referral hospital and all the study participants and for assisting in the data entry process.

Our thanks are also extended to Fantayenesh Gebiru, Tegibelu Awraris and Workye Hailu for giving support in this research processing.

\section{References}

[1] Bern, C., Martines, J., de Zoysa, I. and Glass, R.I. (1992) The Magnitude of the Global Problem of Diarrhoeal Disease: A Ten-Year Update. Bulletin of the World Health Organization, 70, 705-714.

[2] Woldemichael, G. (2001) Diarrhoeal Morbidity among Young Children in Eritrea: Environmental and Socioeconomic Determinants. Journal of Health, Population and Nutrition, 19, 83-90.

[3] Child Health Research Project (1998) Childhood Diarrhoea in Sub-Saharan Africa. Special Report, 2, 4-7.

[4] Ketsela, T. (1991) Knowledge, and Practice of Mothers/Caretakers towards Diarrhoea and Its Treatment in Rural Communities in Ethiopia. Ethiopan Medical Journal, 29, 213-224.

[5] Larson, C.P. and Ketsela, T. (1993) Acute Childhood Diarrhea1. In: Kloos, H. and Zein, Z. A., Eds., The Ecology of Health and Disease in Ethiopia, Westview Press, Oxford, 203-210.

[6] Central Statistics Authority \& ORC Marco (2001) Ethiopia Demographic and Health Survey 2000. The Authority, ORC Macro in Addis Ababa, Calverton, Maryland, USA.

[7] Mekasha, A., Lemma, F. and Shiferaw, T. (1995) Child Health Problems in Ethiopia. EPHA Expert Group Report. Ethiopian Journal of Health Development, 9, 189-192.

[8] Shamebo, D., Muhe, L., Sandstrom, A. and Wall, S. (1991) The Butajira Rural Health Project in Ethiopia: Mortality Pattern of the Under-Fives. Journal of Tropical Pediatrics, 37, 254-261. http://dx.doi.org/10.1093/tropej/37.5.254

[9] Shamebo, D., Muhe, L., Sandstrom, A., Freij, L., Krantz, I. and Wall, S. (1994) The Butajira Rural Health Project in Ethiopia: A Nested Case-Referent (Control) Study of Under-Five Mortality and Its Health and Behavior Determinants. Annals of Tropical Paediatrics, 14, 201-209.

[10] Timaeus, I.M. and Lush, L. (1995) Intra-Urban Differentials in Child Health. Health Transition Review, 5, $163-190$.

[11] Van Derslice, J., Popkin, B. and Briscoe, J. (1994) Drinking Water Quality, Sanitation and Breastfeeding: Their Interactive Effects on Infant Health. Bulletin of the World Health Organization, 72, 589-601.

[12] Mock, N.B., Sellers, T.A., Abdoh, A.A. and Franklin, R.R. (1993) Socioeconomic, Environmental, Demographic and Behavioral Factors Associated with the Occurrence of Diarrhoea in Young Children. Social Science \& Medicine, 36, 807-816. http://dx.doi.org/10.1016/0277-9536(93)90041-2

[13] Manun'ebo, M.N., Haggerty, P.A., Kalengaie, M., Ashworth, A. and Kirkwood, B.R. (1994) Influence of Demographic, Socioeconomic, Environmental Variables on Childhood Diarrhoea in a Rural Areas of Zaire. Journal of Tropical Medicine and Hygiene, 97, 31-38.

[14] Asnake, M. (1991) Water Handling Practices and Their Association with Childhood Diarrhoea. MPH Thesis, Addis Ababa University, Addis Ababa.

[15] Asefa, M., Drewett, R. and Tessema, F. (2000) A Birth Cohort Study in Southwest Ethiopia to Identify Factors Associated with Infant Mortality That Are Amenable for Intervention. Ethiopian Journal of Health Development, 14, 161168.

[16] Oni, G.A. (1996) Infant Feeding Practices, Socioeconomic Conditions and Diarrhoeal Disease in a Traditional Area of Urban Ilorin, Nigeria. East African Medical Journal, 73, 283-288.

[17] McLennan, J.D. (1998) Knowledge and Practice of Preventing Diarrhoea in Malnourished children. Journal of Diarrhoeal Diseases Research, 16, 235-240.

[18] Mbori-Ngacha, D.A., Otieno, J.A., Njeru, E.K. and Onyango, F.E. (1995) Prevalence of Persistent Diarrhoea in Children Aged 3 - 36 Months at the Kenyata National Hospital, Nairobi, Kenya. East African Medical Journal, 72, 711-714.

[19] Muhe, L., Freij, L., Byass, P., Sandstrom, A. and Wall, S. (1997) A One-Year Community Study of Under-Fives in Rural Ethiopia: Patterns of Morbidity. Ethiopian Journal of Health Development, 11, 361-367.

[20] Teklemariam, S., Getaneh, T. and Bekele, F. (2000) Environmental Determinants of Diarrhoea Morbidity in Under-Five Children. Keffa-Sheka Zone. Southwest Ethiopia. Ethiopian Medical Journal, 38, 27-34.

[21] Getaneh, T., et al. (1997) Diarrhoea Morbidity in Urban Area of Southwest Ethiopia. East African Medical Journal, 74, 491-494. 
[22] Ali, M., Asfaw, T., Beyene, H., Byass, P., Hisabu, M.S. and Pedersen, F.K. (2001) A Community Based Study of Childhood Morbidity in Tigray, Northern Ethiopia. Ethiopian Journal of Health Development, 15, 165-172.

[23] Tessema, T., Hailu, S., Anberbir, S. and Mitikie, G. (2001) Household Illness Prevalence and Its Determinants in the Under-Five Children. Ethiopian Journal of Health Development, 15, 173-178.

[24] Kaba, M. and Ayele, F. (2000) Ethnographic Study of Diarrhoeal Disease among Under-Five Children in Mana District, Jimma Zone, Southwest Ethiopia. Ethiopian Journal of Health Development, 14, 77-83. http://dx.doi.org/10.4314/ejhd.v14i1.9932

[25] Jongpiputvanich, S., et al. (1998) Difficulties in Conducting Participatory Action Research to Event Diarrhoea in a Slum Area of Bangkok. Journal of Diarrhoeal Diseases Research, 16, 187-193.

[26] Kinfu, Y. (1992) Maternal Education and Child Survival in Addis Ababa. Ethiopian Journal of Health Development, 6 , 11-15.

[27] Root, G.P.M. (2001) Sanitation, Community Environment and Childhood Diarrhoea in Rural Zimbabwe. Journal of Health, Population and Nutrition, 19, 73-82.

[28] Rustein, S.O. (2000) Factors Associated with Trends in Infant and Child Mortality in Developing Countries during the 1990s. Bulletin of WHO, 78, 1256-1270.

[29] Mitike, G. (2001) Prevalence of Acute and Persistent Diarrhoea in North Gondar Zone, Ethiopia. East African Medical Journal, 78, 44-48. http://dx.doi.org/10.4314/eamj.v78i8.8997

[30] Pelto, G.H. (1991) The Role of Behavioral Research in the Prevention and Management of Invasive Diarrhoea. Reviews of Infectious Diseases, 13, S255-S258.

[31] Mintz, E.D., et al. (1995) Safe Water Treatment and Storage in the Home: A Practical Strategy to Prevent Water Borne Diseases. JAMA, 273, 948-953. http://dx.doi.org/10.1001/jama.1995.03520360062040 